\title{
Faktor-faktor yang Mempengaruhi Kepuasan dan Loyalitas Pelanggan di Restoran selama Pandemik Covid-19
}

\author{
Kezia Stevany*, Axel Gian Aditama*, Agrita Alba Rosalina*, Felicia Tri Sulistyo*, \\ Valerian Andre*, Istijanto* \\ *Universitas Prasetiya Mulya, Jakarta \\ Magister Manajemen \\ J1. R.A.Kartini, Cilandak Barat, Jakarta Selatan, Jakarta 12430 \\ E-mail: kezia.stevany@student.pmbs.ac.id
}

\begin{abstract}
Abstrak
Penelitian mengenai restoran cepat saji di JABODETABEK masih sangat sedikit walaupun konsumsi makanan cepat saji di Indonesia terus meningkat. Terlebih lagi belum ada penelitian mengenai restoran cepat saji pada masa pandemi COVID-19 di JABODETABEK. Penelitian ini memiliki tujuan untuk mengkaji pengaruh kualitas makanan, harga, lokasi dan lingkungan, kualitas layanan, kenikmatan sosial, kebersihan terhadap kepuasan pelanggan serta pengaruh kepuasan tersebut terhadap kesetiaan pelanggan pada restoran cepat saji di JABODETABEK pada masa pandemi COVID-19. Google Forms digunakan untuk mengumpulkan data penelitian. Menggunakan teknik purposive sampling dengan 341 responden yang dipilih. Analisis data menggunakan perangkat lunak SPSS versi 26. Penelitian ini menemukan bahwa kualitas makanan, harga, kualitas layanan, kenikmatan sosial, serta kebersihan memiliki efek positif dan signifikan terhadap kepuasan pelanggan dengan kebersihan menjadi faktor yang paling mempengaruhi kepuasan pelanggan di restoran cepat saji. Lokasi dan lingkungan tidak memiliki pengaruh secara signifikan terhadap kepuasan pelanggan. Kepuasan pelanggan memiliki efek positif terhadap kesetiaan pelanggan pada restoran cepat saji di JABODETABEK.
\end{abstract}

Kata Kunci: kepuasan pelanggan, kepuasan, loyalitas pelanggan, restoran cepat saji, COVID-19

\begin{abstract}
Research on customer loyalty in the fast food restaurants in JABODETABEK is still scarce despite the increase in fast food consumption in Indonesia. Moreover, there has been no research on fast food restaurants during COVID-19 pandemic in JABODETABEK. The purpose of this research is to analyze the effect of food quality, price, location and environment, service quality, social enjoyment, cleanliness on customer satisfaction and the effect of customer satisfaction on consumer loyalty in the fast food restaurants in JABODETABEK during COVID-19 pandemic. Data collection techniques using Google Forms. There were 341 respondents chosen by purposive sampling technique as samples of this study. Methods of data analysis using SPSS version 26. The result of this study shows that food quality, price, service quality, social enjoyment, and cleanliness had a positive effect on customer satisfaction with cleanliness being the most influencing factor of customer satisfaction. On the other hand, location and environment had insignificant effect on customer satisfaction. Meanwhile, customer satisfaction has a positive effect on customer loyalty in the fast food restaurants in JABODETABEK.
\end{abstract}

Keywords: customer satisfaction, quality, customer loyalty, fast food restaurant, COVID-19 


\section{Pendahuluan}

Konsumsi makanan cepat saji di Indonesia semakin meningkat. Berdasarkan survei Statista.com kepada 38.955 responden yang menetap di Indonesia dengan usia di atas 18 tahun, sebanyak $36.81 \%$ dari responden mengkonsumsi makanan cepat saji 1-3 kali setiap minggunya pada tahun 2018. Menurut Radio Republik Indonesia (RRI), saat ini konsumsi makanan dan minuman cepat saji meningkat setiap tahunnya. Pernyataan tersebut didukung oleh data konsumsi makanan cepat saji menyumbang $28 \%$ dari kalori total yang dikonsumsi penduduk di perkotaan.

Menurut BPS, perkembangan usaha penyediaan makanan dan minuman di DKI Jakarta sendiri pada tahun 2018 mengalami peningkatan laba. Jumlah pendapatan usaha penyediaan makanan dan minuman adalah sebesar pada tahun 2017 adalah 22,82 triliun rupiah dan tahun 2018 adalah sebesar 23,55 triliun rupiah, angka tersebut mengalami peningkatan sebanyak $3,11 \%$ pada tahun 2018. Hal tersebut menandakan bahwa industri penyediaan makanan dan minuman semakin berkembang tiap tahunnya. Peningkatan serupa juga terjadi pada restoran cepat saji. Pertumbuhan penjualan dan pertumbuhan restoran cepat saji di Indonesia yang ditunjukkan dengan persen CAGR (Compound Annual Growth Rate). Persen CAGR atau laju pertumbuhan majemuk tahunan restoran cepat saji di Indonesia dari tahun 2015 - 2019 adalah sebesar 12.1\% dan JABODETABEK (Jakarta, Bogor, Depok, Tangerang, Bekasi) merupakan daerah yang memiliki restoran cepat saji paling banyak di Indonesia. Hasil penelitian [1], menunjukkan bahwa 10 restoran cepat saji yang paling sering dikunjungi baik untuk dine-in maupun untuk take away atau home delivery di JABODETABEK yaitu KFC, Restoran Padang Sederhana, McDonald's, Pizza Hut, Solaria, Hoka Hoka Bento, D’Cost, A\&W, Burger King, dan Es Teler 77.

Seiring dengan meningkatnya pertumbuhan restoran cepat saji di Indonesia khususnya di JABODETABEK, maka restoran cepat saji dihadapkan pada persaingan yang ketat. Restoran cepat saji dituntut menjaga relasi dengan para pelanggan dan menyediakan layanan yang berkualitas untuk para pelanggan [2]. Bisnis yang berfokus pada kebutuhan pelanggan (customer needs) menyebabkan tingginya kepuasan pelanggan (customer satisfaction) yang pada akhirnya dapat membangun kesetiaan pelanggan (customer loyalty). Dalam sebuah bisnis, kepuasan pelanggan dan kesetiaan pelanggan berperan besar dalam memperoleh laba [3]. Maka dari itu, restoran cepat saji harus dapat memahami kebutuhan dan keinginan pelanggan agar tercipta kepuasan yang membangun kesetiaan pelanggan.

[4] meneliti mengenai pengaruh kualitas makanan, harga, kualitas layanan, serta lokasi dan lingkungan, terhadap kepuasan pelanggan dan pengaruh kepuasan pelanggan terhadap kesetiaan pelanggan di restoran cepat saji. Temuan penelitian tersebut menyatakan bahwa kualitas makanan, kualitas layanan, dan harga yang wajar memiliki pengaruh positif-signifikan pada kepuasan pelanggan, yang akhirnya mempengaruhi kesetiaan pelanggan restoran cepat saji. Penelitian serupa juga dilakukan oleh [5] yang menemukan bahwa kualitas layanan, kenikmatan sosial, kebersihan, dan kewajaran harga juga secara signifikan berpengaruh terhadap kepuasan pelanggan restoran cepat saji.

Studi mengenai faktor-faktor pengaruh kepuasaan dan kesetiaan pelanggan restoran cepat saji di Indonesia, khususnya di JABODETABEK masih sangat sedikit terlebih pada masa pandemi COVID-19 yang memungkinkan terjadinya pergeseran pola perilaku konsumen dari restoran cepat saji tersebut [6]. Maka, peneliti bermaksud untuk menganalisis lebih lanjut pengaruh kualitas makanan, harga, lokasi dan lingkungan, kualitas layanan, kenikmatan sosial, dan kebersihan restoran cepat saji terhadap kepuasan dan kesetiaan pelanggan restoran cepat saji di JABODETABEK di masa pandemi COVID-19. Penelitian ini diharapkan dapat bermanfaat dalam praktik bisnis restoran cepat saji dan untuk penelitian selanjutnya.

\section{Tinjauan Pustaka}

Industri makanan cepat saji terus berkembang di seluruh dunia. Indonesia merupakan salah satu tempat yang memiliki perkembangan industri makanan cepat saji yang signifikan, oleh sebab itu dibutuhkan asosiasi yang baik antara pelanggan dengan kualitas pelayanan sehingga dapat menyokong perkembangan industri makanan cepat saji [2]. Pelayanan yang ditawarkan oleh perusahaan jasa seperti restoran umumnya bersifat intangible atau tidak berwujud tetapi terdapat juga produk berwujud yang juga berperan dalam menentukan kepuasan pelanggan. Faktor yang berwujud dan tidak berwujud keduanya sangat penting untuk kesetiaan pelanggan. Kategori makanan yang ditawarkan dan kualitas dari layanan adalah hal yang membuat pelanggan menentukan pilihan restoran yang ingin didatangi dan kesetiaan dari pelanggan [7]; [8].

Saat ini pelanggan memiliki banyak pilihan dalam memilih restoran, dan perkembangan dari industri makanan cepat saji yang meningkat memicu persaingan dalam industri makanan cepat saji sehingga restoran cepat saji bersaing dalam meningkatkan hubungan dengan pelanggan [9]. Kesetiaan pelanggan menjadi komponen penting dalam membangun relasi yang baik dengan pelanggan [10]. Pada umumnya, kesetiaan muncul karena

8 | Jurnal Akuntansi, Ekonomi dan Manajemen Bisnis | Vol. 9 No.1, July 2021, 7-16 | E-ISSN: 2548-9836 
pelanggan tersebut merasa puas [11]; [12]. [4] menyebutkan bahwa persepsi kualitas makanan, harga, dan kualitas pelayanan menjadi faktor penentu kepuasan pelanggan. Kepuasan pelanggan merupakan faktor perantara yang berada di antara kualitas makanan, harga, dan kualitas pelayanan dengan kesetiaan pelanggan. Kualitas pelayanan menurut Uddin memiliki faktor positif terkuat yang mempengaruhi kepuasan pelanggan. Penelitian yang dilakukan menambahkan dua faktor ekstra untuk diteliti di Indonesia yaitu kenikmatan sosial dan kebersihan dalam mempengaruhi kepada kepuasan pelanggan. Dalam menguatkan hubungan pelanggan dan restoran makanan cepat saji, diperlukan pengetahuan akan kebutuhan pelanggan, dan pengaturan marketing yang efektif, serta mendorong adanya pekerjaan operasional dan marketing yang lebih baik yang dapat meningkatkan kesetiaan pelanggan, dan akhirnya memberikan keuntungan dalam jangka waktu yang panjang.

Kualitas makanan tentunya dapat berpengaruh pada kepuasan pelanggan, apabila kualitas makanan yang dihidangkan tidak baik, tentu pelanggan akan berpikir untuk mencari tempat lain ketika membeli makanan mereka. Menurut [13], kepuasan pelanggan merupakan hasil persepsi yang diperoleh dari sebuah transaksi. Hasil penelitian [14] memperlihatkan kualitas produk mempengaruhi kepuasan pelanggan secara positif tapi tidak secara signifikan mempengaruhi loyalitas pelanggan.

Harga dari makanan di restoran cepat saji berpengaruh terhadap kepuasan karena apabila harga yang dibayarkan dipersepsikan tidak sesuai dengan makanan yang disajikan, mungkin akan timbul rasa tidak puas dalam benak pelanggan. Kepuasan pelanggan sangat penting, restoran cepat saji perlu memperhatikan faktor-faktor yang dapat membuat pelanggan puas, contohnya yaitu harga dan kenyamanan layanan [15]. Menurut [16], kepuasan pelanggan di restoran cepat saji dipengaruhi oleh kualitas harga dan kualitas layanan secara parsial atau individu.

Lokasi dan lingkungan restoran cepat saji terdiri dari elemen berwujud seperti bangunan restoran, desain eksterior dan interior juga elemen tak berwujud seperti suasana lingkungan, suhu, pencahayaan, wangi, serta musik. Untuk menghasilkan customer experience yang bermakna, lokasi dan lingkungan perlu dioperasikan dengan baik untuk membuat pelanggan puas, ingin kembali lagi, hingga akhirnya timbul kesetiaan pelanggan. [17] serta [18] menemukan bahwa lingkungan fisik mempengaruhi kepuasan pelanggan, namun [4] memiliki pendapat lain, dimana temuannya menunjukkan bahwa lokasi dan lingkungan tidak mempengaruhi kepuasan pelanggan.

Kualitas layanan dari sebuah restoran cepat saji dinilai berdasarkan kesopanan dan keramahan karyawan, pengetahuan karyawan akan makanan dan minuman, kecepatan dan ketepatan layanan, serta cara pelayanan yang digunakan. [19] menyatakan bahwa pelanggan akan termotivasi membangun relasi kuat dengan perusahaan karena kualitas layanan yang baik. Relasi tersebut memungkinkan perusahaan untuk memahami kebutuhan pelanggan dalam jangka panjang dengan cara menyajikan pengalaman maksimal dan menyenangkan serta meniadakan yang kurang menyenangkan sehingga pelanggan memiliki tingkat kepuasan tinggi. Hal ini juga didukung oleh [4]; [5]; [20] yang hasil penelitiannya menunjukan pengaruh positif kualitas layanan pada kepuasan pelanggan restoran cepat saji.

Pelanggan yang datang ke suatu restoran selain untuk memesan makan juga memiliki kebutuhan akan hiburan dan kebutuhan sosial seperti makan bersama dengan keluarga maupun bertemu dengan kerabat. [21] berpendapat bahwa social value memiliki pengaruh positif terhadap kepuasan pelanggan sehingga berpengaruh juga terhadap intensi pembelian. [22] menemukan bahwa hedonic value berpengaruh terhadap intensitas pembelian di restoran cepat saji di Korea dimana restoran cepat saji tidak hanya dipandang sebagai tempat makan namun juga sebagai tempat sosial yang dapat mendatangkan perasaan menyenangkan. Penelitian [5] menemukan hal serupa bahwa bahwa kenikmatan sosial merupakan salah satu customer value dan dapat memiliki pengaruh signifikan terhadap kepuasan pelanggan.

Kebersihan suatu restoran akan mempengaruhi experience pelanggan saat makan di restoran cepat saji dan mempengaruhi kepuasan pelanggan. Penelitian [22] menemukan bahwa kebersihan merupakan atribut kedua terpenting setelah rasa makanan di restoran cepat saji, atribut ini juga berkorelasi positif dengan hedonic value yang akan mempengaruhi intensitas pembelian pelanggan. Hasil penelitian [23] menyatakan kebersihan restoran berpengaruh pada kepuasan pelanggan. Kebersihan restoran cepat saji dapat menjadi lebih penting di masa pandemi COVID-19 karena berhubungan dengan kesehatan masyarakat secara umum.

Bisnis yang berfokus pada kebutuhan pelanggan menyebabkan tingginya kepuasan pelanggan dan memberikan keuntungan bagi bisnis tersebut. Kepuasan pelanggan dapat membangun kesetiaan pelanggan dimana pelanggan akan repurchase dan merekomendasikan kepada merekomendasikan kepada orang lain. Hal ini turut didukung oleh berbagai penelitian seperti [4]; [5]; [15] bahwa kepuasaan mempengaruhi kesetiaan pelanggan secara signifikan. [18] berpendapat serupa bahwa kesetiaan pelanggan dipengaruhi secara signifikan oleh kepuasan pelanggan, penelitian tersebut juga menemukan ol. 9 No.1, July 2021, 7-16 | E-ISSN: 2548-9836 
kebahagiaan yang timbul dari kepuasan berperan sebagai faktor perantara terhadap kesetiaan pelanggan.

Dengan demikian, berdasarkan argumen di atas, dapat dijelaskan bahwa:

H1: Kualitas makanan memiliki efek positif terhadap kepuasan pelanggan.

H2: Harga memiliki efek positif terhadap kepuasan pelanggan.

H3: Lokasi dan lingkungan memiliki efek positif terhadap kepuasan pelanggan.

H4: Kualitas layanan memiliki efek positif terhadap kepuasan pelanggan.

H5: Kenikmatan sosial memiliki efek positif terhadap kepuasan pelanggan.

H6: Kebersihan memiliki efek positif terhadap kepuasan pelanggan.

H7: Kepuasan pelanggan memiliki efek positif terhadap kesetiaan pelanggan.

\section{Metodologi}

Studi ini dilaksanakan dengan studi empirikal pada masyarakat yang melakukan makan di tempat (dine-in) di JABODETABEK yang merupakan daerah dengan jumlah penduduk terbanyak. Pola konsumsi masyarakat JABODETABEK cenderung mengalami perubahan karena padatnya kesibukan sehingga menjadikan makanan cepat saji sebagai pilihan makanan untuk mempermudah dan menghemat waktu.

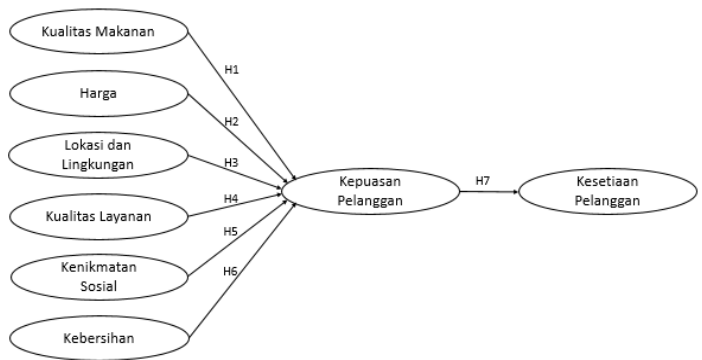

Gambar 1: Model struktural variabel penelitian

Pengumpulan data primer dari populasi penelitian menggunakan kuesioner yang dibagikan melalui google forms selama 1 minggu dari tanggal 10 Agustus 2020 hingga 17 Agustus 2020. Kuesioner yang digunakan mengacu pada penelitian sebelumnya [4]; [5]. Kuesioner terdiri dari 10 bagian, yaitu pertanyaan penyaring (3 pertanyaan), kualitas makanan (4 pernyataan), harga (4 pernyataan), lokasi dan lingkungan (5 pernyataan), kualitas layanan (4 pernyataan), kenikmatan sosial (3 pernyataan), kebersihan (4 pernyataan), kepuasan pelanggan (2 pernyataan), kesetiaan pelanggan (4 pernyataan), dan demografi responden (7 pertanyaan). Bagian kedua sampai dengan sepuluh yang berisi pernyataan dinilai menggunakan skala likert dengan bobot satu sampai tujuh, dimana (1) merupakan bobot untuk STS-Sangat Tidak Setuju, (2) merupakan bobot untuk TS-Tidak Setuju, (3) merupakan bobot ATS-Agak Tidak Setuju, ATS-Agak Tidak Setuju, (4) merupakan bobot untuk N-Netral, (5) merupakan bobot untuk AS-Agak Setuju, (6) merupakan bobot untuk SSetuju dan (7) merupakan bobot untuk SS-Sangat Setuju.

Penelitian ini memiliki beberapa variabel diantaranya variabel eksogen (independen) yaitu Kualitas Makanan $\left(\mathrm{X}_{1}\right)$, Harga $\left(\mathrm{X}_{2}\right)$, Lokasi dan Lingkungan $\left(\mathrm{X}_{3}\right)$, Kualitas Layanan $\left(\mathrm{X}_{4}\right)$, Kenikmatan Sosial $\left(\mathrm{X}_{5}\right)$ dan Kebersihan $\left(\mathrm{X}_{6}\right)$ sebagai ; variabel intervening yaitu Kepuasan Pelanggan $\left(\mathrm{Y}_{1}\right)$; dan variabel endogen (dependen) yaitu Kesetiaan Pelanggan $\left(\mathrm{Y}_{2}\right)$ Model penelitian digambarkan pada Gambar 1. Populasi yang diteliti adalah semua masyarakat yang berdomisili di JABODETABEK yang makan di restoran cepat saji dalam 3 bulan terakhir. Menurut [24], segmen yang memiliki suatu karakteristik dan jumlah tertentu dari populasi adalah sampel Maka, sampel dari penelitian ini adalah sebagian masyarakat yang berdomisili di JABODETABEK yang makan di restoran cepat saji dalam 3 bulan terakhir.

Terdapat 2 macam teknik sampling, yaitu nonprobability sampling dan probability sampling. Perbedaan kedua macam teknik sampling tersebut yaitu pada probability sampling setiap anggota populasi mempunyai peluang yang sama menjadi sampel penelitian, sementara itu pada nonprobability sampling peluang untuk menjadi sampel penelitian tidak sama [24]. Penelitian ini dijalankan dengan metode nonprobability sampling dan teknik sampling purposive [24]. Pertimbangan sampling berdasarkan penilaian peneliti mengenai kesesuaian karakteristik yang dimiliki dengan tujuan penelitian, seperti masyarakat yang makan ditempat dalam 3 bulan terakhir di restoran cepat saji dan di daerah JABODETABEK.

Analisis data penelitian menggunakan metode analisis kuantitatif dengan SPSS versi 26. Uji validitas dan reliabilitas dilakukan untuk menguji kualitas data, sementara analisis linier berganda untuk menguji hipotesis. Masyarakat yang makan di tempat di restoran cepat saji di JABODETABEK merupakan objek dari penelitian ini.

Berdasarkan survei yang dilakukan, dari 392 responden yang pernah makan di tempat (dine in) di restoran cepat saji dalam 3 bulan terakhir (Mei-Agustus 2020), hanya terdapat sebanyak 341 responden yang masuk ke dalam kriteria sampel penelitian. Responden tersebut dine-in di restoran cepat saji seperti KFC, McDonalds, Hokben, A\&W, dan Burger King di JABODETABEK.

Sebanyak 341 orang yang masuk dalam kriteria sampel tersebut dilakukan analisis responden berdasarkan: (1) jenis kelamin dan (2) usia. Tabel I menjelaskan demografi dari responden berdasarkan jenis kelamin, umur dan domisili. 
TABEL I

PROFIL RESPONDEN

\begin{tabular}{|l|r|r|}
\hline Classification & Frequency & \% \\
\hline Jenis Kelamin & 203 & 59.50 \\
\hline Laki-laki & 138 & 40.0 \\
\hline Perempuan & $\mathbf{3 4 1}$ & $\mathbf{1 0 0 . 0 0}$ \\
\hline Total & \multicolumn{3}{|c|}{21} & 6.16 \\
\hline Umur & 154 & 45.16 \\
\hline Dibawah 18 tahun & 141 & 41.35 \\
\hline $18-24$ tahun & 23 & 6.74 \\
\hline $25-34$ tahun & 2 & 0.59 \\
\hline $35-49$ tahun & 0 & 0.00 \\
\hline $50-64$ tahun & $\mathbf{3 4 1}$ & $\mathbf{1 0 0 . 0 0}$ \\
\hline 65 tahun ke atas & & \\
\hline Total & & \\
\hline
\end{tabular}

\section{Hasil dan Pembahasan}

Terdapat delapan variabel yang digunakan dalam pengujian validitas dan reliabilitas, yaitu kualitas makanan, harga, lokasi dan lingkungan, kualitas layanan, kenikmatan sosial, kebersihan, kepuasan pelanggan, dan kesetiaan pelanggan dengan total 31 pernyataan. Uji validitas menunjukan nilai loading factor $>0.50$ dan uji reliabilitas menunjukan skor Cronbach's Alpha $>0.70$ yang artinya 31 pernyataan tersebut valid dan reliabel.

Nilai adjusted $R$ Square dari uji koefisien determinasi adalah 0.641. Angka ini menunjukan kualitas makanan, harga, lokasi dan lingkungan, kualitas layanan, kenikmatan sosial, dan kebersihan mempengaruhi kepuasan pelanggan ketika dine-in di restoran cepat saji sebesar $64.1 \%$ dan ada faktor pengaruh kepuasan pelanggan lainnya di luar variabel penelitian sebesar 35.9\%.

Signifikansi $0.000<0.05$ menandakan kelayakan model untuk dilakukan uji pengaruh variabel independen terhadap variabel intervening. Jumlah sampel (n) dalam penelitian ini sebesar 341 dan terdapat 6 variabel independen $(\mathrm{k})$. Berdasarkan data tersebut, diperoleh nilai dari $\mathrm{F}$ tabel sebesar 0.27 dengan ketentuan df1 $=\mathrm{k}$, dan $\mathrm{df} 2=\mathrm{n}-\mathrm{k}-1$, dimana df $1=6$ dan df $2=334$. $\mathrm{F}$ hitung sebesar 102.028 lebih besar daripada $F$ tabel 0.27 yang artinya enam variabel independen secara bersamaan memiliki efek signifikan (Sig 0.000) terhadap variabel intervening kepuasan pelanggan dalam dine-in di restoran cepat saji. Hasil uji koefisien determinasi dan uji $\mathrm{f}$ dapat dilihat pada Tabel III.

Pada Tabel IV dapat dilihat bahwa variabel kualitas makanan, harga, kualitas layanan, kenikmatan sosial, dan kebersihan memiliki efek yang signifikan terhadap kepuasan pelanggan dengan signifikansi $<0.05$ sedangkan variabel lokasi dan lingkungan tidak memiliki pengaruh yang signifikan dengan signifikansi $>0.05$.

TABEL II

\begin{tabular}{|c|c|c|c|}
\hline Construct & Item & $\begin{array}{c}\text { St } \\
\text { load } \\
\cdot \\
\text { Fact } \\
\text { or }\end{array}$ & $\begin{array}{c}\text { Cron } \\
\text { bach } \\
\text { Alph } \\
\text { a }\end{array}$ \\
\hline \multirow{4}{*}{$\begin{array}{l}\text { Kualitas } \\
\text { Makanan } \\
\quad\left(\mathrm{X}_{1}\right)\end{array}$} & $\begin{array}{l}\text { Rasa makanan di restoran } \\
\text { cepat saji tersebut lezat. } \\
\left(\mathrm{X}_{11}\right)\end{array}$ & .734 & \multirow{4}{*}{.732} \\
\hline & $\begin{array}{l}\text { Restoran cepat saji } \\
\text { tersebut memiliki variasi } \\
\text { menu yang beragam. } \\
\left(\mathrm{X}_{12}\right)\end{array}$ & .748 & \\
\hline & $\begin{array}{l}\text { Restoran cepat saji } \\
\text { tersebut menyediakan } \\
\text { makanan dalam kondisi } \\
\text { segar. }\left(\mathrm{X}_{13}\right)\end{array}$ & .763 & \\
\hline & $\begin{array}{l}\text { Restoran cepat saji } \\
\text { tersebut mempertahankan } \\
\text { suhu makanan yang tepat. } \\
\left(\mathrm{X}_{14}\right)\end{array}$ & .756 & \\
\hline \multirow{4}{*}{ Harga $\left(X_{2}\right)$} & $\begin{array}{l}\text { Harga makanan di } \\
\text { restoran cepat saji } \\
\text { tersebut bersaing. }\left(\mathrm{X}_{21}\right)\end{array}$ & .845 & \multirow{4}{*}{.749} \\
\hline & $\begin{array}{l}\text { Harga makanan di } \\
\text { restoran cepat saji } \\
\text { tersebut masuk akal. }\left(\mathrm{X}_{22}\right)\end{array}$ & .856 & \\
\hline & $\begin{array}{l}\text { Sistem pembayaran di } \\
\text { restoran cepat saji } \\
\text { tersebut baik dan mudah } \\
\text { dilakukan (contoh: } \\
\text { dengan tunai, kartu atau } \\
\text { e-payment). }\left(\mathrm{X}_{23}\right) \\
\end{array}$ & .629 & \\
\hline & $\begin{array}{l}\text { Restoran cepat saji } \\
\text { tersebut sering } \\
\text { menawarkan "penawaran } \\
\text { spesial" atau "promosi } \\
\text { khusus". }\left(\mathrm{X}_{24}\right)\end{array}$ & .677 & \\
\hline \multirow{5}{*}{$\begin{array}{l}\text { Lokasi dan } \\
\text { lingkungan } \\
\qquad\left(\mathrm{X}_{3}\right)\end{array}$} & $\begin{array}{l}\text { Pengaturan tempat parkir } \\
\text { di restoran cepat saji } \\
\text { tersebut sudah baik. }\left(\mathrm{X}_{31}\right)\end{array}$ & .782 & \multirow{5}{*}{.704} \\
\hline & $\begin{array}{l}\text { Restoran cepat saji } \\
\text { tersebut memiliki } \\
\text { penempatan meja dan } \\
\text { kursi makan yang } \\
\text { memadai dan nyaman. } \\
\left(\mathrm{X}_{32}\right) \\
\end{array}$ & .748 & \\
\hline & $\begin{array}{l}\text { Di restoran cepat saji } \\
\text { tersebut terdapat ruang } \\
\text { bermain untuk anak-anak. } \\
\left(\mathrm{X}_{33}\right) \\
\end{array}$ & .577 & \\
\hline & $\begin{array}{l}\text { Restoran cepat saji } \\
\text { tersebut terletak di lokasi } \\
\text { yang strategis. }\left(X_{34}\right)\end{array}$ & .668 & \\
\hline & $\begin{array}{l}\text { Desain restoran cepat saji } \\
\text { tersebut menarik. }\left(\mathrm{X}_{35}\right)\end{array}$ & .673 & \\
\hline $\begin{array}{l}\text { Kualitas } \\
\text { layanan } \\
\left(\mathrm{X}_{4}\right) \\
\end{array}$ & $\begin{array}{l}\text { Karyawan di restoran } \\
\text { cepat saji tersebut sopan } \\
\text { dan ramah. }\left(\mathrm{X}_{41}\right)\end{array}$ & .867 & .756 \\
\hline
\end{tabular}




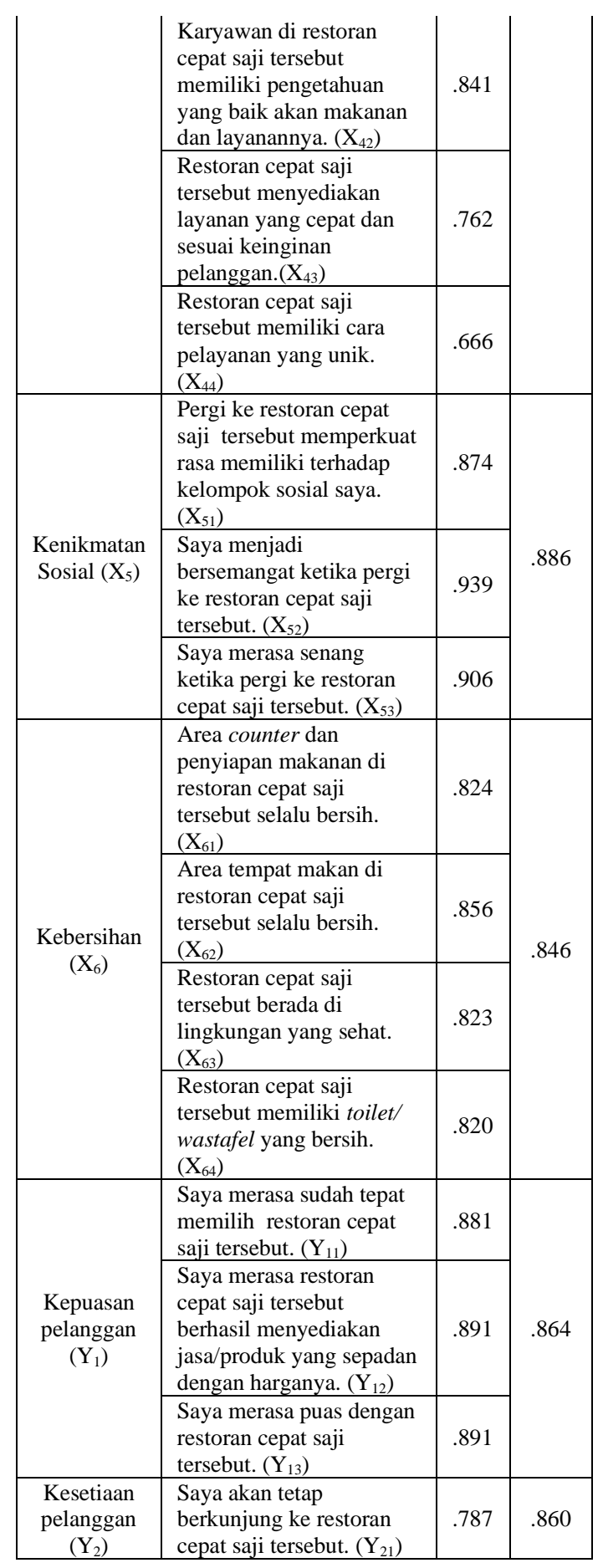

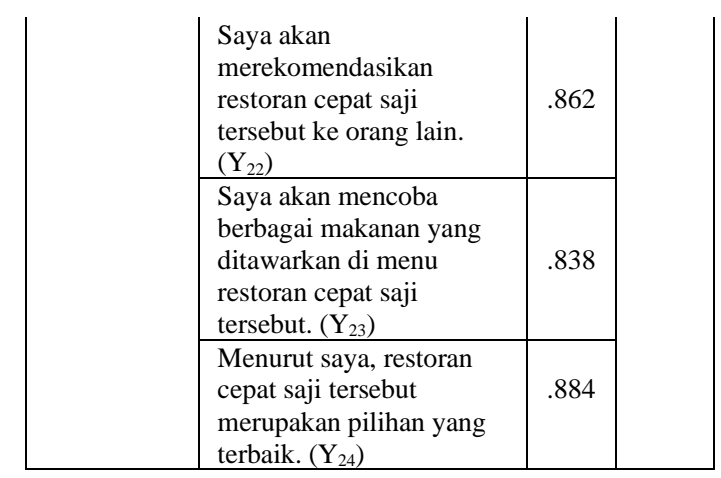

TABEL III

MODEL SUMMARY DAN ANOVA VARIABEL KUALITAS MAKANAN, HARGA, LOKASI DAN LINGKUNGAN, KUALITAS LAYANAN, KENIKMATAN SOSIAL, DAN KEBERSIHAN TERHADAP VARIABEL KEPUASAN PELANGGAN

\begin{tabular}{|c|c|c|c|c|}
\hline Model & $\begin{array}{c}\text { Adjusted R } \\
\text { Square }\end{array}$ & $\mathrm{df}$ & $\mathrm{F}$ & $\mathrm{Sig}$ \\
\hline 1 & 0.641 & 6 & 102.028 & $.000^{\mathrm{a}}$ \\
\hline
\end{tabular}

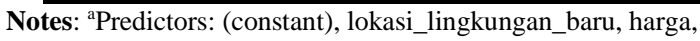
kenikmatan_sosial, kualitas_makanan, kebersihan, kualitas_layanan; bdependent variable: kepuasan pelanggan

TABEL IV

HASIL ANALISIS REGRESI LINIER BERGANDA (PERSAMAAN I) Coefficients $^{\mathrm{a}}$

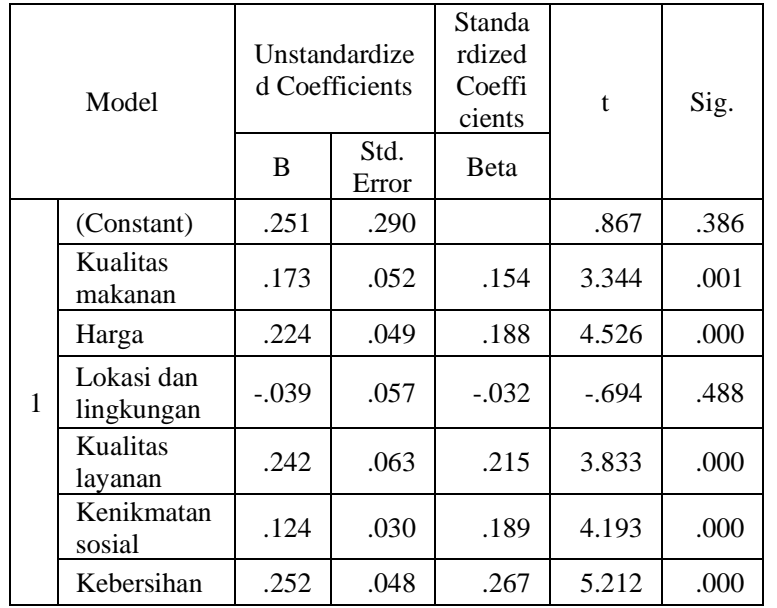

a. Dependent Variable: Kepuasan Pelanggan

Sumber: Hasil Olahan Data dengan Program SPSS 26 
Analisis regresi kedua dilakukan untuk mengetahui pengaruh variabel intervening: kepuasan pelanggan terhadap variabel dependen: kesetiaan pelanggan. Berdasarkan analisis koefisien determinasi dan uji $\mathrm{f}$ dalam Tabel $\mathrm{V}$, didapatkan hasil adjusted $\mathrm{R}^{2}$ yaitu 0.569 , artinya $56.9 \%$ variabel kepuasan pelanggan mempengaruhi kesetiaan pelanggan dan ada faktor pengaruh kesetiaan pelanggan lainnya di luar variabel penelitian sebesar $43.1 \%$.

Nilai signifikansi $0.000<0.05$ menunjukkan bahwa model tersebut memiliki kelayakan untuk pengujian pengaruh variabel intervening terhadap variabel dependen. Jumlah sampel (n) dalam penelitian ini sebesar 341 dan terdapat 1 variabel dependen (k). Berdasarkan data tersebut, diperoleh nilai dari $\mathrm{F}$ tabel sebesar 0.004 dengan ketentuan $\mathrm{df} 1=\mathrm{k}$, dan df $2=\mathrm{n}-\mathrm{k}-1$, dimana df $1=1$ dan df 2 $=339$ dan df merupakan derajat bebas (degree of freedom). $\mathrm{F}$ hitung sebesar 449.236 lebih besar daripada $\mathrm{F}$ tabel $=0.004$ yang artinya variabel intervening secara bersamaan memiliki pengaruh yang signifikan (Sig 0.000) terhadap variabel dependen dalam dine-in di restoran cepat saji. Hasil uji koefisien determinasi dan uji $\mathrm{f}$ dapat dilihat pada Tabel V.

TABEL V

MODEL SUMMARY DAN ANOVA VARIABEL KEPUASAN PELANGGAN TERHADAP VARIABEL KESETIAAN PELANGGAN

\begin{tabular}{|c|c|c|c|c|}
\hline Model & $\begin{array}{c}\text { Adjusted } \\
\text { R Square }\end{array}$ & df & F & Sig \\
\hline 1 & 0.569 & 1 & 449.236 & $.000^{\mathrm{a}}$ \\
\hline
\end{tabular}

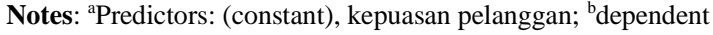
variable: kesetiaan pelanggan

Hasil analisis uji t pada Tabel VI, menunjukkan bahwa ada pengaruh signifikan antara kepuasan pelanggan terhadap kesetiaan pelanggan dalam dine-in di restoran cepat saji.

\section{TABEL VI}

HASIL ANALISIS REGRESI LINIER BERGANDA (PERSAMAAN II)

\begin{tabular}{|c|c|c|c|c|c|c|}
\hline \multirow{2}{*}{\multicolumn{2}{|c|}{ Model }} & \multicolumn{2}{|c|}{$\begin{array}{c}\text { Unstandardized } \\
\text { Coefficients }\end{array}$} & \multirow{3}{*}{$\begin{array}{c}\begin{array}{c}\text { Standardized } \\
\text { Coefficients }\end{array} \\
\text { Beta }\end{array}$} & \multirow{3}{*}{$\begin{array}{c}\mathrm{t} \\
3.092\end{array}$} & \multirow{3}{*}{$\begin{array}{l}\text { Sig. } \\
.00 \\
2\end{array}$} \\
\hline & & \multirow{2}{*}{$\begin{array}{c}\mathrm{B} \\
.756\end{array}$} & \multirow{2}{*}{$\begin{array}{l}\begin{array}{c}\text { Std. } \\
\text { Error }\end{array} \\
.244\end{array}$} & & & \\
\hline \multirow{2}{*}{1} & (Constant & & & & & \\
\hline & $\begin{array}{l}\text { Kepuasan } \\
\text { pelanggan }\end{array}$ & .862 & .041 & .755 & 21.195 & $\begin{array}{r}.00 \\
0\end{array}$ \\
\hline
\end{tabular}

a. Dependent Variable: Kesetiaan Pelanggan

Sumber: Hasil Olahan Data dengan Program SPSS 26

\section{Pembahasan}

Penelitian ini menunjukkan bagaimana ke-6 variabel persepsi konsumen tentang kualitas makanan, harga, kualitas layanan, kenikmatan sosial dan kebersihan berperan terhadap kepuasan dan kesetiaan pelanggan restoran cepat saji di JABODETABEK. Hasil penelitian menunjukkan bahwa kualitas makanan $\left(\mathrm{X}_{1}\right)$, harga $\left(\mathrm{X}_{2}\right)$, kualitas layanan $\left(\mathrm{X}_{4}\right)$, kenikmatan sosial $\left(\mathrm{X}_{5}\right)$, dan kebersihan $\left(\mathrm{X}_{6}\right)$, berpengaruh terhadap kepuasan pelanggan $\left(\mathrm{Y}_{1}\right)$ sedangkan variabel lokasi dan lingkungan $\left(\mathrm{X}_{3}\right)$ tidak memiliki pengaruh signifikan terhadap kepuasan pelanggan. Secara berurutan dari yang terbesar pengaruhnya yaitu variabel kebersihan $\left(\mathrm{X}_{6}\right)$, diikuti dengan variabel kualitas layanan $\left(\mathrm{X}_{4}\right)$, kenikmatan sosial $\left(\mathrm{X}_{5}\right)$, harga $\left(\mathrm{X}_{2}\right)$ dan yang terakhir adalah kualitas makanan $\left(\mathrm{X}_{1}\right)$.

Variabel kebersihan $\left(\mathrm{X}_{6}\right)$ yang paling berpengaruh terhadap kepuasan pelanggan $\left(\mathrm{Y}_{1}\right)$ dapat dikaitkan dengan meningkatnya kepedulian dan kesadaran masyarakat terhadap kebersihan di masa pandemi COVID-19. Hasil dari penelitian ini sedikit berbeda dengan dengan [5] yang juga melakukan penelitian kepuasan pelanggan di restoran cepat saji dengan kebersihan pada urutan ketiga yang mempengaruhi kepuasaan pelanggan setelah kualitas layanan dan harga.

Kualitas layanan $\left(\mathrm{X}_{4}\right)$ mempengaruhi kepuasan pelanggan secara positif dan signifikan, artinya jika kualitas layanan semakin baik maka akan membuat pelanggan semakin puas. Pengaruh yang diberikan oleh persepsi masyarakat terhadap kualitas layanan $\left(\mathrm{X}_{4}\right)$ masih belum sebesar kebersihan $\left(\mathrm{X}_{6}\right)$ mengingat kondisi pandemi COVID-19 yang menyebabkan berubahnya persepsi masyarakat tentang lebih pentingnya kebersihan $\left(\mathrm{X}_{6}\right)$ dibandingkan dengan kualitas layanan dari sebuah restoran cepat saji.

Kenikmatan sosial $\left(\mathrm{X}_{5}\right)$ membuktikan bahwa meskipun tujuan utama seorang pelanggan adalah untuk menyantap santapan di restoran cepat saji, kenikmatan untuk menyantap makanan bersama kelompok sosial pelanggan tersebut dapat mempengaruhi kepuasan pelanggan $\left(\mathrm{Y}_{1}\right)$. Hal tersebut dibuktikan dengan pengaruh kenikmatan sosial $\left(\mathrm{X}_{5}\right)$ yang lebih besar daripada harga $\left(\mathrm{X}_{2}\right)$. Harga merupakan tolak ukur yang penting dalam meningkatkan kepuasan pelanggan namun nilai pengaruh harga terhadap kepuasan lebih rendah dibandingkan dengan kenikmatan sosial. Hal ini menjadi pengetahuan baru bagi pemilik, bahwa kenikmatan sosial menjadi lebih berarti dibandingkan dengan harga yang dibayarkan. Makan bersama dan menghabiskan waktu bersama sambil menyantap makanan, dianggap lebih menarik oleh pelanggan dibandingkan dengan biaya yang dikeluarkan untuk membeli makanan tersebut. Variabel harga $\left(\mathrm{X}_{2}\right)$ sejalan dengan kepuasan pelanggan. Hasil ini berbeda dengan penelitian [25] yang menemukan bahwa kewajaran terhadap terhadap harga tidak memiliki hasil signifikan pada kepuasan pelanggan restoran cepat saji. Disisi lain banyak penelitian lain yang mendukung hasil penelitian 
penulis dimana harga berpengaruh positif pada kepuasan pelanggan, seperti pada penelitian [4]; [16]; [26]. Oleh karena itu penulis berpendapat jika harga yang diberikan terjangkau dan sesuai dengan harapan pelanggan, tentu akan meningkatkan kepuasan pelanggan.

[27] mengatakan bahwa perlu dilakukan penelitian mengenai pengaruh kualitas produk dan harga terhadap kepuasan pelanggan. Kualitas makanan (X1) adalah salah satu parameter dari karakteristik makanan seperti warna, bentuk, ukuran, tekstur, konsistensi, dan rasa yang dapat diterima oleh konsumen. Diterimanya hipotesis alternatif pertama menunjukkan bahwa kualitas makanan (X1) memiliki hasil signifikan terhadap kepuasan pelanggan (Y1). Artinya, kualitas makanan yang semakin baik membuat pelanggan semakin puas, namun kualitas makanan memiliki pengaruh terkecil dibandingkan dengan variabel kebersihan, kualitas layanan, kenikmatan sosial, dan harga. Hal ini dikarenakan dengan seiring berkembangnya zaman, sebagian besar restoran cepat saji menyediakan menu serupa, dengan bumbu dan tampilan produk sebagai pembeda. Hasil penelitian [28] menunjukkan bahwa kualitas produk sebuah restoran cepat saji dapat meningkatkan kepuasan pelanggan.

Secara teoritis, ketika lokasi dan lingkungan restoran cepat saji strategis bagus dan menarik, tingkat kepuasan pelanggan meningkat. Hasil penelitian menunjukkan lokasi dan lingkungan $\left(\mathrm{X}_{3}\right)$ tidak memiliki hasil signifikan terhadap kepuasan pelanggan $\left(\mathrm{Y}_{1}\right)$. Hal ini diduga karena sebagian besar restoran cepat saji membuka banyak cabang restoran di banyak titik di JABODETABEK. Selain itu, restoran cepat saji menyediakan jasa pengantaran makanan yang berbiaya murah dan berjamurnya aplikasi layanan pesan-antar makanan seperti GoFood dan GrabFood mempermudah konsumen untuk membeli makanan serta minuman secara daring dengan cepat dan nyaman. Hasil uji hipotesis ini mendukung analisis [4] yang mengungkapkan lokasi dan lingkungan tidak memiliki hasil signifikan terhadap kepuasan pelanggan. Meskipun lokasi merupakan salah satu faktor yang penting dalam memasarkan suatu produk pada konsumen menurut [29], bercermin dari hasil penelitian ini maupun penelitian [4], maka bagi para pemilik restoran cepat saji, lebih baik menggunakan dana investasi yang tersedia untuk meningkatkan kebersihan $\left(\mathrm{X}_{6}\right)$ restoran sebagai faktor yang paling mempengaruhi kepuasan pelanggan dibandingkan dengan menggunakan dana tersebut untuk membuat ruang bermain anak $\left(\mathrm{X}_{33}\right)$, memilih lokasi yang strategis $\left(\mathrm{X}_{34}\right)$, atau mendesain ruangan restoran menjadi lebih menarik $\left(\mathrm{X}_{35}\right)$ khususnya di era pandemi COVID-19.

Variabel kepuasan pelanggan $\left(\mathrm{Y}_{1}\right)$ memiliki hasil yang sejalan dengan kesetiaan pelanggan $\left(\mathrm{Y}_{2}\right)$ hal ini dapat membuktikan bahwa pelanggan yang puas terhadap restoran cepat saji pasti akan menjadikan restoran cepat saji tersebut menjadi restoran favoritnya dan bersedia untuk tetap setia membeli di restoran cepat saji tersebut. Hal ini didukung oleh penelitian [4]; [5] menunjukkan bahwa kepuasaan mempengaruhi kesetiaan pelanggan secara signifikan. Menurut [25], kepuasan pelanggan dapat dikatakan sebagai variabel yang memiliki pengaruh terbesar kepada kesetiaan pelanggan. Penelitian yang telah dilaksanakan diharapkan menambah wawasan baru pada industri makanan cepat saji yang ada di Indonesia terutama daerah JABODETABEK.

\section{Kesimpulan}

Penelitian ini bertujuan untuk memberikan kontribusi dalam memahami berbagai faktor yang mempengaruhi kepuasan pelanggan dan kesetiaan pelanggan di industri restoran cepat saji di JABODETABEK, Indonesia. Hasil studi menyatakan bahwa persepsi pelanggan tentang kualitas makanan, harga, kualitas layanan, kenikmatan sosial, dan kebersihan adalah berbagai faktor penting dalam menentukan kepuasan pelanggan. Faktor terpenting yaitu faktor kebersihan karena memiliki pengaruh positif terbesar terhadap kepuasan pelanggan dibandingkan faktor lain. Hal ini dikarenakan dunia sedang mengalami pandemi COVID19, membuat pelanggan cemas akan kesehatannya dan mulai memperhatikan prosedur kebersihan yang diterapkan oleh masing-masing restoran cepat saji. Faktor lokasi dan lingkungan tidak memiliki pengaruh positif-signifikan terhadap kepuasan pelanggan dalam penelitian ini. Kepuasan pelanggan memiliki efek positif dan signifikan terhadap kesetiaan pelanggan restoran cepat saji yang artinya bahwa semakin puas pelanggan terhadap restoran cepat saji maka pelanggan tersebut akan semakin setia dengan melakukan pembelian berulang maupun merekomendasikan restoran cepat saji kepada kerabat.

Secara teoritis, penelitian ini mendukung penelitianpenelitian terdahulu bahwa kualitas makanan, harga dan kualitas layanan adalah komponen yang berpengaruh kepada kepuasan pelanggan. Selain itu, penelitian ini memperkaya penelitian terdahulu bahwa ada faktor lain yaitu kenikmatan sosial dan kebersihan yang mempengaruhi kepuasan pelanggan restoran cepat saji.

Implikasi manajerial dari riset ini merupakan pentingnya restoran cepat saji meningkatkan kebersihan disaat pandemi COVID-19 sehingga dapat kompetitif bersaing di dalam industri. Peningkatan keunggulan kebersihan dilakukan dengan memberikan rasa aman kepada pelanggan saat mengkonsumsi makanan dan minuman, dan saat dine-in di restoran cepat saji tersebut. Restoran cepat saji juga perlu memperhatikan faktor kualitas makanan, harga, kualitas layanan, dan kenikmatan 
sosial agar membuat pelanggan puas dan pada akhirnya menjadi pelanggan yang setia.

Penelitian ini memiliki keterbatasan wilayah penelitian karena hanya menjangkau wilayah JABODETABEK. Saran bagi penelitian selanjutnya dapat menambahkan variabel seperti digitalisasi, ekspektasi pelanggan dan promosi (Hal ini dimaksud agar dapat menganalisis adanya variabel-variabel lain yang mungkin memiliki pengaruh terhadap kepuasan pelanggan) serta menggunakan wilayah yang lebih luas pada objek penelitian yang selanjutnya, karena penelitian ini hanya menjangkau wilayah JABODETABEK. Selain itu, penelitian dapat dilakukan untuk jenis restoran lain seperti fine dining, family-style, buffet, dan lain - lain.

\section{Daftar Pustaka}

A. Roy Morgan. (2018). Restoran Sederhana \& KFC battle to be top Indonesian restaurant. Diakses pada Oktober 11, 2020 dari http://www.roymorgan.com/findings/7614indonesia-eating-habits-eating-in-out-qsrrestaurants-march-2018-201806010644

B. Saleem, H. and Raza, N.S. (2014), "The impact of service quality on customer satisfaction, customer loyalty and brand image: evidence from hotel industry of Pakistan", Middle-East Journal of Scientific Research, 19(5):706-711.

C. Best, R. J. 2014. Market Based Management: 6th Edition. United Kingdom: Pearson Education Limited.

D. Uddin, M.B. (2019), "Customer Loyalty in the Fast Food Restaurants of Bangladesh", British Food Journal, 121(11): 2791-2808.

E. Gallarza-Granizo, M.G., Maria-Eugenia, R., Christopher, S. (2020), "Customer Value in Quick-Service Restaurants: A cross-cultural study", International Journal of Hospitality Management, 85.

F. Lawi, G.F.K. (2019). Begini Pergeseran Perilaku Konsumen Baru selama Pandemi Covid-19. Diakses pada Oktober 10, 2020 dari https://ekonomi.bisnis.com/read/20200515/12/ $1240921 /$ begini-pergeseran-perilakukonsumen-baru-selama-pandemi-covid-19

G. Clark, A.C. and Wood, R.C. (1998), "Consumer loyalty in the restaurant industry: a preliminary exploration of the issues",
International Journal of Contemporary Hospitality Management, 10(4):139-144.

H. Han, H., Nguyen, H.N., Song, H., Chua, B.-L., Lee, S. and Kim, W. (2018), "Drivers of brand loyalty in the chain coffee shop industry", International Journal of Hospitality Management, 72(1):86-97.

I. Momtaz, N.J., Alizadeh, S. and Vaghefi, M.S. (2013), "A new model for assessment fast food customer behavior case study: an Iranian fast-food restaurant", British Food Journal, 115(4):601-613

J. Al-Ansi, A., Olya, H.G.T. and Han, H. (2018), "Effect of general risk on trust, satisfaction, and recommendation intention for halal food", International Journal of Hospitality Management (in press)

K. Carranza, R., Díaz, E. and Martín-Consuegra, D. (2018), "The influence of quality on satisfaction and customer loyalty with an importance-performance map analysis: exploring the mediating role of trust", Journal of Hospitality and Tourism Technology, 9(3):380-396.

L. Espinosa, J.A., Ortinau, D.J., Krey, N. and Monahan, L. (2018), "I'll have the usual: how restaurant brand image, loyalty, and satisfaction keep customers coming back", Journal of Product \& Brand Management, 27 (6):599614.

M. Jahanshahi, A. A., Gashi, M. A. H., Mirdamadi, S. A., Nawaser, K., \& Khaksar, S. M. S. (2011), "Study the effects of customer service and product quality on customer satisfaction and loyalty", International Journal of Humanities and Social Science, 1(7), 253260.

N. Yesenia. (2014), "Pengaruh Kualitas Layanan dan Produk terhadap Kepuasan serta Loyalitas Pelanggan KFC di Tangerang Selatan”, Jurnal Manajemen dan Organisasi, 5(3).

O. Kaura, V., Prasad, D., Sharma, S. (2015), "Service quality, service convenience, price and fairness, customer loyalty, and the mediating role of customer satisfaction", International Journal of Bank Marketing, 33(4): 404-422.

P. Fiazisyah, A. dan Niken, P. (2018), "Pengaruh Kualitas Produk, Harga Dan Kualitas Pelayanan Terhadap Kepuasan Konsumen Restoran Cepat Saji KFC Basuki Rahmat Surabaya", E-Jurnal Boga, 7 (2)

Q. Hanaysha, J. (2016), "Testing the Effects of Food Quality, Price Fairness, and Physical Environment on Customer Satisfaction in Fast Food Restaurant 
Industry", Journal of Asian Business Strategy. 6.

10.18488/journal.1006/2016.6.2/1006.2.31.40.

R. Zhong, Y.P., Moon, H.C. (2020), "What Drives Customer Satisfaction, Loyalty, and Happiness in Fast-Food Restaurants in China? Perceived Price, Service Quality, Food Quality, Physical Environment Quality, and the Moderating Role of Gender", MDPI Journals Foods, 9

S. Panjaitan, J. dan Yuliati, Ai. (2016), "Pengaruh Kualitas Pelayanan Terhadap Kepuasan Pelanggan Pada JNE Cabang Bandung [The Influence of Service Quality on Customer Satisfaction at JNE Branch in Bandung]",

DeReMa (Development Research of Management): Jurnal Manajemen. 11. 265. 10.19166/derema.v11i2.197.

T. Hartono, K. (2013), "Pengaruh kualitas layanan terhadap kepuasan pelanggan dalam membentuk loyalitas pelanggan McDonald's basuki rahmat Surabaya", Jurnal Ilmiah Mahasiswa Universitas Surabaya, 2(2), 1-20.

U. Sung, H.Y., Kim, J.J., Youn, M.K. (2014), “A Study upon Effects of Family Restaurant Consumption Values upon Satisfaction, Reliability and Behavioural Intentions in Korea: Focused on College Students at Metropolitan Area", The Journal of Asian Finance, Economics and Business, 1(4): 29-37.

V. Park, C. (2004), "Efficient or enjoyable? Consumer values of eating-out and fast food restaurant consumption in Korea", International Journal of Hospitality Management, 23: 87-94.

W. Truong, N., Nisar, T., Knox, D., Prabhakar, G. (2017), "The Influences of Cleanliness and Employee Attributes on Perceived Service Quality in Restaurants in a Developing Country", International Journal Culture, Tourism, and Hospitality Research, 11(4):608627.

X. Sugiyono. (2015). Metode Penelitian Pendidikan Kuantitatif, Kualitatif, dan R\&D. Bandung: Penerbit Alfabeta.

Y. Etemad-Sajadi, R. and Rizzuto, D. (2013), "The antecedents of consumer satisfaction and loyalty in fast food industry: A cross-national comparison between Chinese and Swiss consumers", International Journal of Quality \& Reliability Management, 30 (7):780-798.

Z. Khan, S., Syed, M.H., Fahad, Y. (2013), "Determinants of Customer Satisfaction in Fast Food Industry A Study of Fast Food Restaurants Peshawar Pakistan”, Studia Commercialia Bratislavensia, 6(21): 56-65.

AA. Nguyen, Q., Nisar, T.M., Knox, D. and Prabhakar, G.P. (2018), "Understanding customer satisfaction in the UK quick service restaurant industry: The influence of the tangible attributes of perceived service quality", British Food Journal, 120(6):1207-1222.

BB. Harahap, R. (2017), "Pengaruh Kualitas Produk Terhadap Kepuasan Pelanggan di Restoran Cepat Saji KFC cbg. Asia Mega Mas, Medan", Jurnal Manajemen dan Informatika Komputer Pelita Nusantara, 1(1), 12-17.

CC. Kotler, P., Gary M.A., dan Almudena E. (2018), Marketing Mix: Selected Chapters From: Principles of Marketing, Seventeenth Edition. USA :Pearson Publishing. 